\title{
Mechanism of improvement of TiN-coated tool life by nitrogen implantation
}

\author{
S.J. Bull \\ Department of Mechanical, Materials and Manufacturing Engineering, University of Newcastle, \\ Newcastle-upon-Tyne, NE1 7RU, United Kingdom \\ Yu.P. Sharkeev \\ Russian Academy of Sciences, Institute for Strength Physics and Materials Science, \\ Tomsk 634021, Russia \\ S.V. Fortuna \\ Tomsk State University, Department of Architecture and Building, Tomsk 634003, Russia \\ I.A. Shulepov \\ Nuclear Physics Institute, Tomsk Polytechnic University, Tomsk 634050, Russia \\ A.J. Perry \\ A.I.M.S. Consulting, 9470, Buchs SG, Switzerland
}

(Received 7 December 2000; accepted 4 September 2001)

The life of TiN-coated tools can be improved by a post-coating ion implantation treatment, but the mechanism by which this occurs is still not clear. Nitrogen implantation of both physical-vapor-deposited TiN and CVD TiN leads to surface softening as the dose increases, which has been attributed to amorphization. In this study a combination of transmission electron microscopy and atomic force microscopy was used to characterize the microstructure of implanted TiN coatings on cemented carbide for comparison with mechanical property measurements (nanoindentation, residual stress, etc.), made on the same samples. Ion implantation leads to a slight reduction in the grain size of the TiN in the implanted zone, but there is no evidence for amorphization. Surface softening is observed for physical-vapor-deposited TiN, but this is probably due to a combination of changes in surface composition and the presence of a layer of bubbles generated by the very high implantation doses used.

\section{INTRODUCTION}

The use of nitrogen ion implantation to improve the performance of cutting tools coated with TiN by physical vapor deposition (PVD) or chemical vapor deposition (CVD) is well established. ${ }^{1-4}$ However, the mechanisms by which these improvements occur are not well understood. Among the reasons suggested for the observed improvements are enhanced hardness, ${ }^{3,5}$ beneficial compressive residual stress, ${ }^{6}$ improved coating adhesion, ${ }^{7}$ and reduced friction/adhesion to the workpiece, ${ }^{3,5}$ which might be due to a lubricating amorphous layer. ${ }^{8,9}$ However, whether these mechanisms are all operating and are sufficient to explain the observed machining results is a question of some debate.

In commercial ion implantation of TiN-coated tools no differentiation is generally made between PVD and CVD coatings as the treatment is thought to be equally effective for both. ${ }^{1,10}$ Similarly a single ion/dose combination (approximately $3 \times 10^{17} \mathrm{~N}_{2}{ }^{+} / \mathrm{cm}^{2}$ ) is generally used to treat all tools, regardless of origin. Some of the previously reported mechanisms by which the nitrogen ion implantation treatment improves the performance of TiN-coated tools have been highly specific to one type of coating and it seems unlikely that any mechanism that is not universal can explain the industrial experience. Therefore it is necessary to determine the behavior of both types of coating in response to nitrogen implantation and look for common features if the factors controlling tool performance are to be understood.

CVD TiN coatings are deposited at around $950{ }^{\circ} \mathrm{C}$ and are composed of fine, equiaxed grains of a zone- 2 type according to Thornton's structural classification. ${ }^{11}$ CVD films have a relatively rough surface $(\mathrm{Ra} \sim 2 \mu \mathrm{m})$ and a low tensile residual stress (typically $<1 \mathrm{GPa}$ ), microstrain broadening, and defect concentration within individual grains. $^{4,12,13}$ In contrast, PVD deposition technologies allow the deposition of columnar, zone-T coatings ${ }^{11}$ at temperatures lower than $500{ }^{\circ} \mathrm{C}$. These coatings tend to be very smooth, with roughness almost the same as the untreated substrate (except for some cathodic arc coatings where macrodroplet formation leads to an increase 
in roughness ${ }^{14}$ ). However, they generally possess a large compressive residual stress (approximately $6 \mathrm{GPa}^{12,13,15}$ ), and individual grains contain a large number of defects leading to high microstrain broadening. Nitrogen ion implantation will generally increase these defect levels for both types of coating (e.g., Ref. 16).

Increasing the defect density within a material will eventually lead to structural instability when the energy associated with the defects can be the driving force for microstructural change. In metals such changes include the formation of extended defects such as dislocations and the reduction of grain size by recovery and recrystallization. ${ }^{17}$ In ceramic materials, where these processes are more difficult, amorphization can occur. ${ }^{18}$ Amorphization has been reported to occur after ion implantation of PVD TiN, ${ }^{19,20}$ whereas no such response has been seen for CVD material implanted with a range of ions. $^{12,21,22}$ Since amorphization due to ion bombardment occurs in response to the accumulation of the damage produced (e.g., the formation of vacancies and interstitials by the displacement of target atoms) this is consistent with the lower baseline defect levels present in CVD coatings. However, it must be questioned whether it is possible to amorphize a material such as TiN in which the bonding is substantially metallic. ${ }^{6}$ These metallic properties are a result of electron transfer from the titanium to the nitrogen leaving one conduction electron per formula unit. ${ }^{23}$

The propensity for a material to undergo amorphization is usually assessed in terms of a critical energy density deposited in displacement collisions, which is related to the ionicity of the material being implanted. ${ }^{24,25}$ The more ionic the material, the higher the energy deposition necessary for amorphization. Based on electronegativity values for $\mathrm{Ti}\left(1.54^{26}\right)$ and $\mathrm{N}\left(13.04^{26}\right)$ the ionicity of TiN is 0.43 , which would predict a critical energy density of $2 \times 10^{23} \mathrm{keV} / \mathrm{cm}^{3}$ using the master curve of Burnett and Page. ${ }^{27}$ This gives an amorphization dose of approximately $4 \times 10^{16} \mathrm{~N}_{2}{ }^{+} / \mathrm{cm}^{2}$ for both PVD and CVD TiN; it does not take into consideration the defects already present in the coating, which will reduce the amorphization dose considerably for the PVD coatings. Since CVD TiN has not been observed to amorphize at doses up to $5 \times 10^{17} \mathrm{~N}_{2}{ }^{+} / \mathrm{cm}^{2}$ this is not consistent with observed behavior. One possible explanation for this is that some defects may be annealed during the implantation process due to beam heating, this is unlikely to be a significant effect given that vacancy annealing in ion-implanted TiN is not significant below $1000{ }^{\circ} \mathrm{C} .{ }^{16}$ It is much more likely that $\mathrm{TiN}$ is not amorphized by nitrogen ion implantation because of the metallic component of its chemical bonding, ${ }^{23}$ metallic materials are more likely to undergo recrystallization and grain refinement after ion implantation except in cases where sufficient quantities of a metalloid $(\mathrm{P}, \mathrm{B})$ are implanted, which promotes the formation of amorphous metals. Since the amorphization of TiN has usually been determined from glancing-angle $\mathrm{x}$-ray diffraction studies, it may be that the observation is a consequence of the test method. For instance if the grain size has been reduced to such an extent that it is no longer visible by this technique, the material will appear amorphous. Changes to surface composition may also have occurred that enable an amorphous layer to be produced by ion implantation.

To determine whether the material is truly amorphous a higher resolution microstructural probe is necessary. For this reason we used transmission electron microscopy (TEM) to investigate the coatings implanted in this study. TEM also allows the observation of dislocations generated in the implanted layer and ejected into the undamaged material beneath. This so-called "long-range effect" of ion implantation ${ }^{28,29}$ is responsible for increased hardness beneath the implanted layer and is an important explanation for the observation that improvements in the wear performance of metals due to ion implantation often persist long after the implanted layer has been completely worn away. ${ }^{30}$ Given the relatively low dislocation mobility in $\mathrm{TiN}$ it might be expected that this mechanism is unlikely to occur in the coatings investigated here. However, the persistence in improved wear performance after the implanted layer is worn away is also observed for ion-implanted TiN-coated tools.

The object of this study was to determine the factors that might explain the improvements in tool performance for nitrogen-implanted TiN deposited by both PVD and CVD. To achieve this, tests were undertaken to examine each of the factors that might influence the performance of both unimplanted TiN coatings and coatings implanted through two different nitrogen doses.

\section{EXPERIMENTAL}

Commercial PVD and CVD TiN-coated cemented carbide inserts were used throughout the study. The TiN coating was at least $7 \mu \mathrm{m}$ thick in all samples to avoid the complicating influence of the substrate. The PVD coatings were deposited using the Balzers plasmaassisted PVD process whereas the CVD coatings were produced in-house at the tool supplier (GTE Valenite, Troy, MI).

All samples were implanted at $90 \mathrm{keV}$ using a nonmass-analyzed bucket ion source at approximately normal incidence at a beam current density of $0.8 \mu \mathrm{A} / \mathrm{cm}^{2}$. The beam contains about $75 \% \mathrm{~N}_{2}{ }^{+}$at $90 \mathrm{keV}$ and $25 \%$ $\mathrm{N}^{+}$at $90 \mathrm{keV}$. It is usually assumed that the $\mathrm{N}_{2}{ }^{+}$splits up on contact with the surface into two nitrogen ions of unknown charge state. The actual dose of $\mathrm{N}^{+}$will thus be $7 / 4$ the nominal dose of $\mathrm{N}_{2}{ }^{+}$and the concentration profile will be given by the sum of the profiles for $90 \mathrm{keV}$ and $45 \mathrm{keV}$ nitrogen implantation, corrected for the effects of sputtering. ${ }^{31}$ Range and damage parameters are 
presented in Table I. Since the combined profile is dominated by $45 \mathrm{kV}$ nitrogen, the peak of the concentration will occur at approximately $64 \mathrm{~nm}$ (Fig. 1). Two nitrogen doses were investigated: $3 \times 10^{17} \mathrm{~N}_{2}^{+} / \mathrm{cm}^{2}$, which is typical of the dose used in tool wear-life improvement, and $1 \times 10^{17} \mathrm{~N}_{2}{ }^{+} / \mathrm{cm}^{2}$, which is not usually as effective in improving tool life. The base pressure of the implantation system was $1 \times 10^{-5}$ torr.

The properties of the films were investigated before and after implantation by $\mathrm{x}$-ray diffraction, nanoindentation, and scratch testing. Details of the x-ray diffraction measurement methods applied to these samples can be found elsewhere. ${ }^{22}$

Nanoindentation experiments were performed using a Nanoindenter II (Nanoinstruments, Knoxville, TN) fitted with a Berkovich diamond indenter. Peak loads in the range 1 to $500 \mathrm{mN}$ were used and the hardness obtained from the unloading part of the load-displacement curves using the method of Oliver and Pharr. ${ }^{32}$ The tip end shape was carefully calibrated prior to testing; the effects of tip blunting are only visible in measurements on fused silica when the contact depth is less than $25 \mathrm{~nm}$, which is less than the thickness of the implanted layers investigated here and therefore should not mask the effects of the implantation treatment. Due to the fact that implantation treatments were carried out on as-received tools where the roughness is significant there is considerable scatter in the nanoindentation results at a given load depending on where the indenter strikes the surface. Polishing the surface prior to testing does reduce this scatter, but since tools are not polished prior to implantation by industry this was not done in this study. To obtain meaningful nanoindentation data it is therefore necessary to average the results from a large number of impressions at each load. For the highest loads each data point represents the average of results from 10 indentations, and the number averaged increases to 30 at the lowest load.

Scratch testing was performed with a Rockwell C diamond stylus $\left(120^{\circ}\right.$ cone, $200 \mu \mathrm{m}$ hemispherical tip radius) fitted to a commercial scratch tester (Teer Coatings, Kidderminster, United Kingdom). A standard scratching speed of $100 \mathrm{~N} / \mathrm{min}$ and table speed of $10 \mathrm{~mm} / \mathrm{min}$ were used for all tests. Three scratches were made to a peak load of $100 \mathrm{~N}$ on each sample. Through-thickness fracture and adhesion failures were observed in all cases. The main adhesion-related failure mode was wedge spallation $^{33}$; the load at which this was first observed was adopted as the critical load criterion. The scratch diamond was inspected by optical profilometry before and after testing to determine if wear was excessive as this is known to affect the critical load for coating detachment. ${ }^{34}$ This can be a particular problem for TiN coatings on cemented carbide substrates. However, since only a few scratches were performed in this study, indenter wear was not significant and no damage could be detected.

The coating structure and morphology were investigated by transmission electron microscopy (TEM), atomic force microscopy (AFM), and high-resolution scanning electron microscopy (HRSEM). To make samples for TEM, a thin plate (approximately $300 \mu \mathrm{m}$ thick) including the coating was cut from the specimen using spark erosion. The plate was then mechanically polished on the side opposite from the coating before $3 \mathrm{~mm}$ discs were cut from it, again by spark erosion. Pulse jet electropolishing of the side opposite to the coating was then performed until a patch of substrate was completely removed. Ion beam sputtering was then used to thin and perforate the disc. For samples from the surface, thinning was carried out from the substrate side only. For samples from other depths within the coating, thinning was carried out from both sides; the sputtering rate of the TiN coatings was calibrated and the time of thinning adjusted to give samples at different depths below the surface. Care was taken to minimize the amount of material that was redeposited during thinning. For some samples a final thinning operation was carried out on the back side to remove any redeposited material,

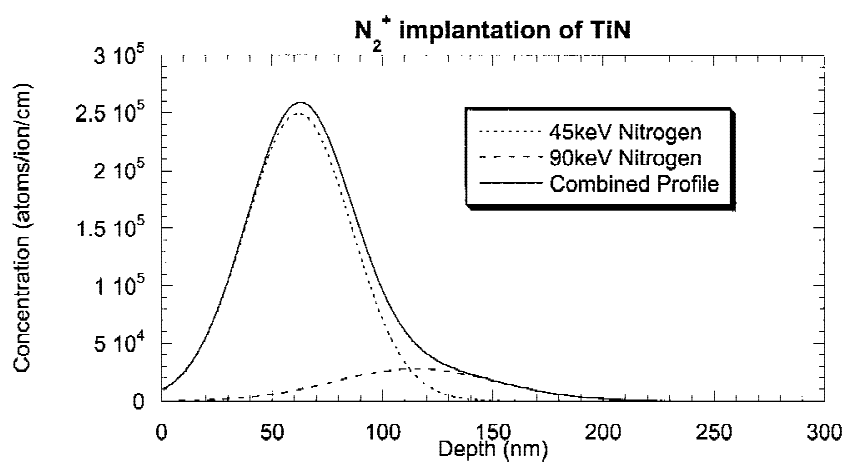

FIG. 1. Predicted concentration profiles for $90 \mathrm{keV} \mathrm{N}_{2}{ }^{+}$implantation calculated from the data in Table I.

TABLE I. Ion beam parameters for the nitrogen ion implantation treatments used. Data determined from the TRIM92 computer package. ${ }^{41}$

\begin{tabular}{cccccc}
\hline \hline Ion & $\begin{array}{c}\text { Energy } \\
(\mathrm{KeV})\end{array}$ & $\begin{array}{c}\text { Ion range, } \\
\mathrm{Rp}(\mathrm{nm})\end{array}$ & $\begin{array}{c}\text { Deviation, } \\
\Delta \mathrm{Rp}(\mathrm{nm})\end{array}$ & $\begin{array}{c}\text { Damage range, } \\
\mathrm{Xd}(\mathrm{nm})\end{array}$ & $\begin{array}{c}\text { Deviation, } \\
\Delta \mathrm{Xd}(\mathrm{nm})\end{array}$ \\
\hline $\mathrm{N}$ & 90 & 115 & 36 & 95 & 30 \\
$\mathrm{~N}$ & 45 & 62 & 24 & 40 & 20 \\
\hline \hline
\end{tabular}

${ }^{\mathrm{a} C a l c u l a t e d ~ f r o m ~ t h e ~ L i n d h a r d ~ p a r t i t i o n ~ f u n c t i o n . ~}{ }^{42}$ 
but this was found to have little effect on the results generated from these foils. This implies that the effects of redeposited material are minimal.

Plan-view TEM specimens were made at two different depths below the surface for all implanted and unimplanted coatings: (i) $100 \mathrm{~nm}$ depth, corresponding approximately to the peak of the nitrogen implantation profile; (ii) $1 \mu \mathrm{m}$ below the surface, below the implanted layer but in the implantation affected zone (IAZ) where dislocation generation has been observed to give a longrange hardening effect previously in CVD TiN. ${ }^{28}$

\section{RESULTS AND DISCUSSION}

\section{A. Hardness from nanoindentation}

Previous results found hardening at low implantation doses followed by softening as the dose increases further. ${ }^{5}$ In this study no hardening was observed for nitrogen implanted CVD TiN [Fig. 2(a)], but a surface softening at $1 \times 10^{17} \mathrm{~N}_{2}{ }^{+} / \mathrm{cm}^{2}$ (which disappeared at the higher dose) was observed for PVD TiN [Fig. 2(b)]. This
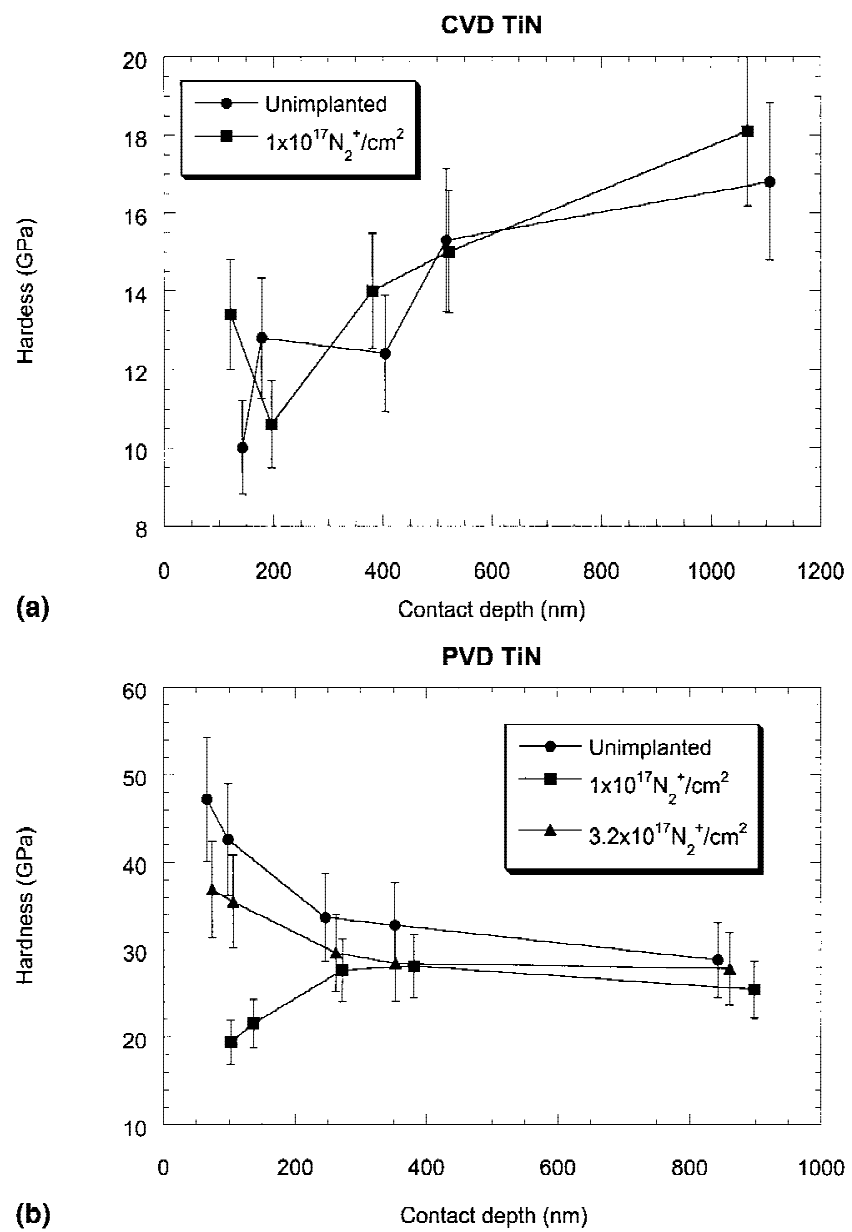

FIG. 2. Variation of hardness with contact depth for nitrogen implanted TiN as a function of dose deposited by (a) CVD and (b) PVD. was also observed recently by other workers. ${ }^{35}$ Since the higher-dose-implanted sample hardness is almost identical to that of the unimplanted coating it is unlikely that hardening due to the implantation process plays a major role in the improvement of tool life.

Surface softening can be an indication that the surface of a ceramic material has been amorphized by the ion implantation technique. ${ }^{23,24}$ However, if this were the case the effect would be expected to increase as the dose increases which is not what was observed in this study.

\section{B. Residual stress}

For $1 \times 10^{17} \mathrm{~N}_{2}{ }^{+} / \mathrm{cm}^{2}$ nitrogen implantation, glancingangle $\mathrm{x}$-ray diffraction results (Fig. 3) show that there is a slight reduction in compressive stress near the surface after implantation into the PVD TiN, but the change for the CVD TiN is marginal. At the higher dose the stress in the PVD coating is identical to that in unimplanted material which is very similar to what has been observed previously. ${ }^{35}$ Given the variability of stress measurements made on different parts of the same coating, the differences after implantation are unlikely to be significant. Differences between the implanted and unimplanted coatings are much smaller at the higher dose and are well within experimental error. Changes in residual stress can therefore not explain the difference in machining performance.

The fact that there is a slight reduction in residual stress near the surface for the PVD TiN coating could suggest that amorphization occurred for this material since stress relief is often observed in conjunction with amorphization in ceramic materials. ${ }^{36}$ However, there are other mechanisms by which this relief could also occur (e.g., bubble formation, see later), so the surface structure must be investigated by other techniques if this effect is to be confirmed.

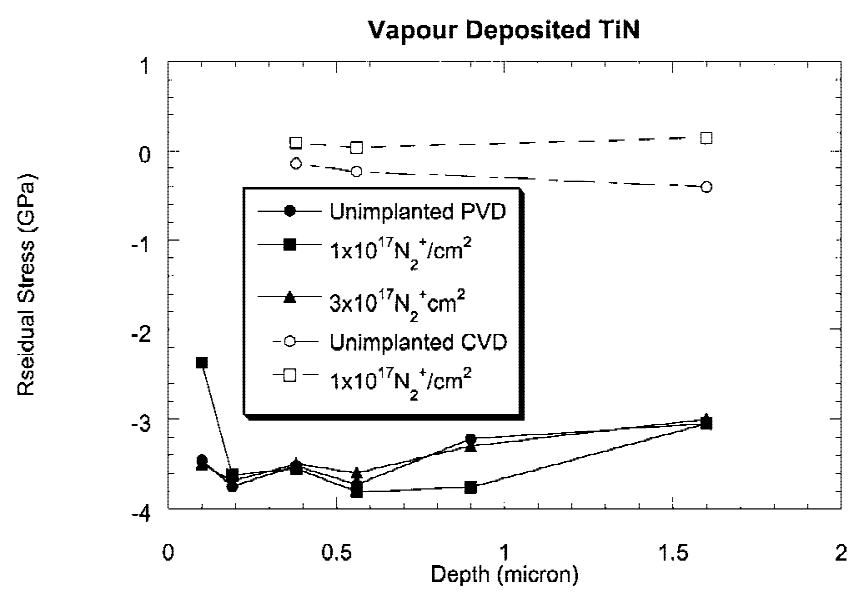

FIG. 3. Variation of residual stress with depth before and after implantation for PVD and CVD TiN. 


\section{Scratch testing}

No implantation treatment had any measurable effect on the critical load for coating detachment in the scratch adhesion test (Table II). Indeed, it is difficult to see how a treatment confined to the outermost layer of the coating which does not change the residual stress within it can have much influence on the coating substrate interface for such a thick layer. Adhesion changes might be significant for thinner coatings ${ }^{7}$ but will not explain the differences in machining behavior observed for the tools in this study.

One difference between the implanted and unimplanted coating observed during the scratch-test was diamond-indenter friction, which was lower after

TABLE II. Parameters determined in the scratch test.

\begin{tabular}{|c|c|c|c|}
\hline Coating & $\begin{array}{c}\text { Dose } \\
\mathrm{N}_{2}^{+} / \mathrm{cm}^{2}\end{array}$ & $\begin{array}{c}\text { Critical load for } \\
\text { coating detachment, } \\
L_{\mathrm{c}}(\mathrm{N})\end{array}$ & $\begin{array}{c}\text { Friction coefficient } \\
\text { at } 30 \mathrm{~N} \\
\text { normal load, } \mu\end{array}$ \\
\hline \multirow[t]{3}{*}{ PVD TiN } & 0 & $52 \pm 3$ & $0.15 \pm 0.02$ \\
\hline & $1 \times 10^{17}$ & $50 \pm 4$ & $0.12 \pm 0.02$ \\
\hline & $3 \times 10^{17}$ & $53 \pm 7$ & $0.13 \pm 0.02$ \\
\hline \multirow[t]{3}{*}{ CVD TiN } & 0 & $75 \pm 10$ & $0.18 \pm 0.04$ \\
\hline & $1 \times 10^{17}$ & $72 \pm 8$ & $0.15 \pm 0.02$ \\
\hline & $3 \times 10^{17}$ & $77 \pm 12$ & $0.12 \pm 0.02$ \\
\hline
\end{tabular}

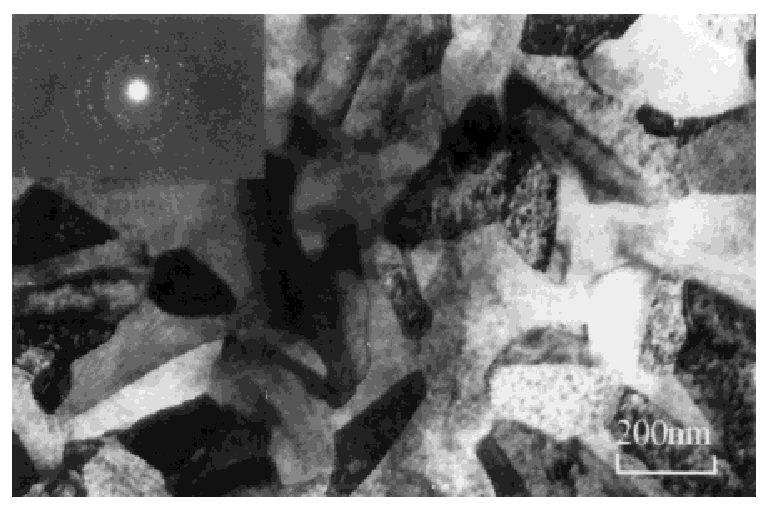

(a)

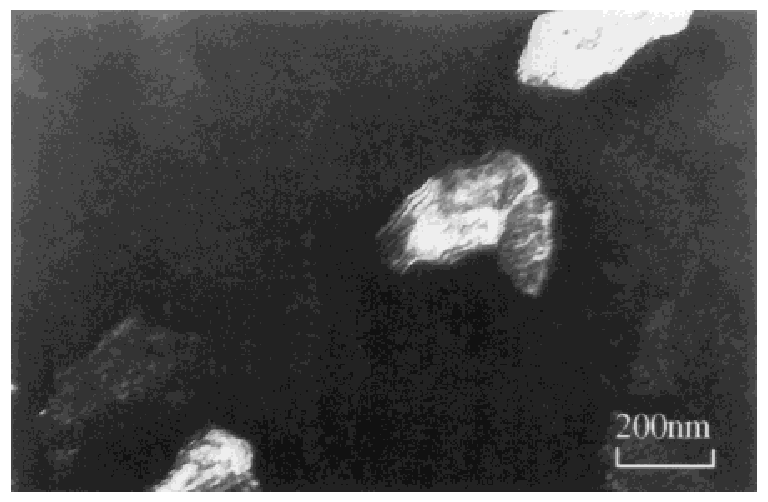

(b)

FIG. 4. Transmission electron micrographs of $1 \times 10^{17} \mathrm{~N}_{2}{ }^{+} / \mathrm{cm}^{2}$ implanted CVD TiN taken $1 \mu \mathrm{m}$ below the surface: (a) bright field and (b) dark field (200) reflection. implantation for both PVD and CVD coatings and at both doses investigated (Table II). A similar reduction in friction was observed previously in pin-on-disk tests by other workers. ${ }^{9}$ There are a number of reasons why this change in friction might occur, including amorphization, changes to surface hardness, changes to surface topography, and changes to surface chemistry. Of these, the changes in surface hardness are not likely to be important- the softer layer on the PVD TiN sample implanted to $1 \times 10^{17} \mathrm{~N}_{2}{ }^{+} / \mathrm{cm}^{2}$ would be expected to give higher friction due to increased ploughing rather than the reduction of friction observed. The other mechanisms are investigated in more detail in the following sections.

\section{Transmission electron microscopy}

For CVD coatings TEM samples taken from $1 \mu \mathrm{m}$ below the surface clearly show the coating grain structure (Fig. 4). However, closer to the surface the structure is less apparent. At $100 \mathrm{~nm}$ depth for the unimplanted and the $1 \times 10^{17} \mathrm{~N}_{2}{ }^{+} / \mathrm{cm}^{2}$ implant (approximately at the peak of the nitrogen implant profile) there is little difference in appearance of the bright-field images (Fig. 5). The grain size is somewhat larger than deeper in the coating. Electron diffraction patterns are also very similar and indicate

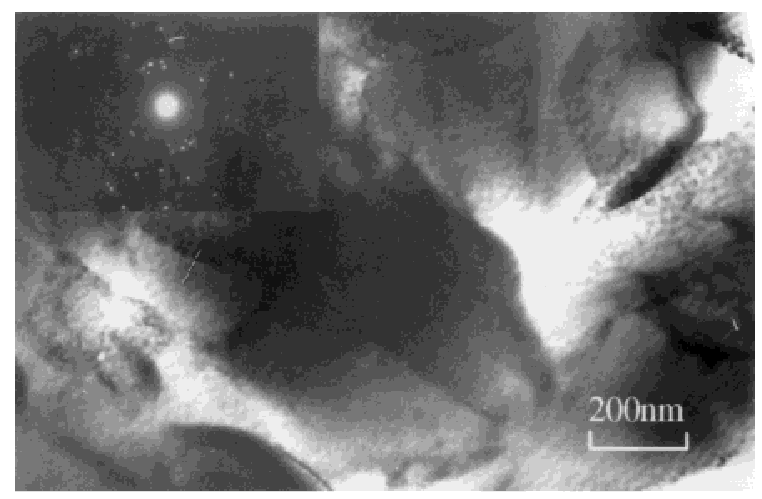

(a)

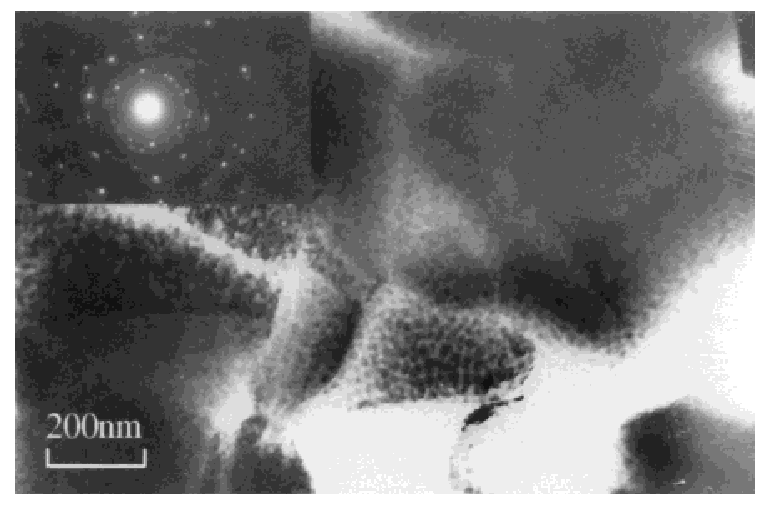

(b)

FIG. 5. Transmission electron micrographs of CVD TiN taken $100 \mathrm{~nm}$ below the sample surface (a) unimplanted and (b) $1 \times 10^{17} \mathrm{~N}_{2}{ }^{+} / \mathrm{cm}^{2}$ implanted. 
polycrystalline material. Well-defined rings are produced rather than the diffuse bands characteristic of amorphous material. Since amorphization is known to occur initially at the peak of the implant profile, it would most likely show in Fig. 5(b) if it occurred. There is no evidence for amorphization at the higher dose either. There is no difference in scalar dislocation density (approximately $1 \times 10^{11} \mathrm{~cm}^{-2}$ ) at $1 \mu \mathrm{m}$ depth in either the implanted or unimplanted material, which would suggest that $90 \mathrm{keV}$ nitrogen implantation into CVD TiN creates little or no long range effect. Previous observations of the existence of a long-range effect in CVD $\mathrm{TiN}^{30}$ were performed on material implanted with a heavy-metal ion (yttrium) where momentum transfer from the ion beam and hence the probability of creating damage is much higher. ${ }^{37}$

For the PVD coatings $100 \mathrm{~nm}$ below the surface, the fine grain size and high defect density mean that individual grains are not visible in bright-field TEM micrographs [Fig. 6(a)] although they can be seen in dark field [Fig. 6(b)]. Again, implantation of $1 \times 10^{17} \mathrm{~N}_{2}{ }^{+} / \mathrm{cm}^{2}$ does not have a major effect on the microstructure. The diffraction patterns show the typical diffuse ring structure indicative of polycrystalline materials, which becomes more diffuse after implantation (i.e., shows more microstrain broadening), but the samples do not show an amorphous halo, which would be expected if amorphization had taken place.

At the higher implantation dose, the result is the same (Fig. 7). There is no evidence for amorphous material, though there is a slight reduction in grain size near the

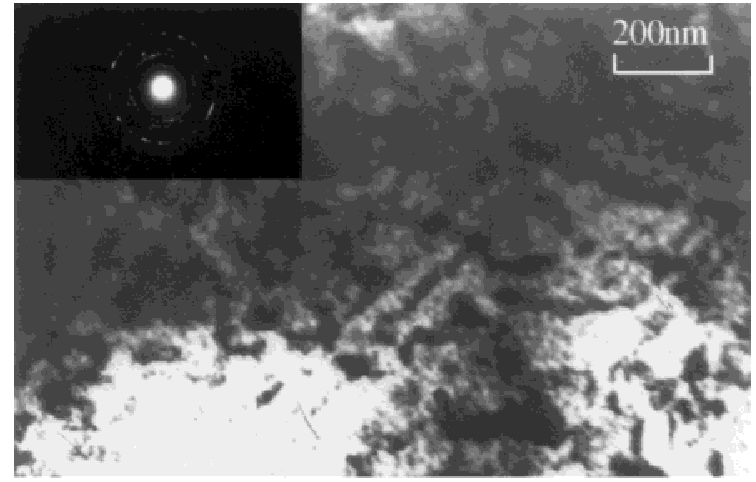

(a)

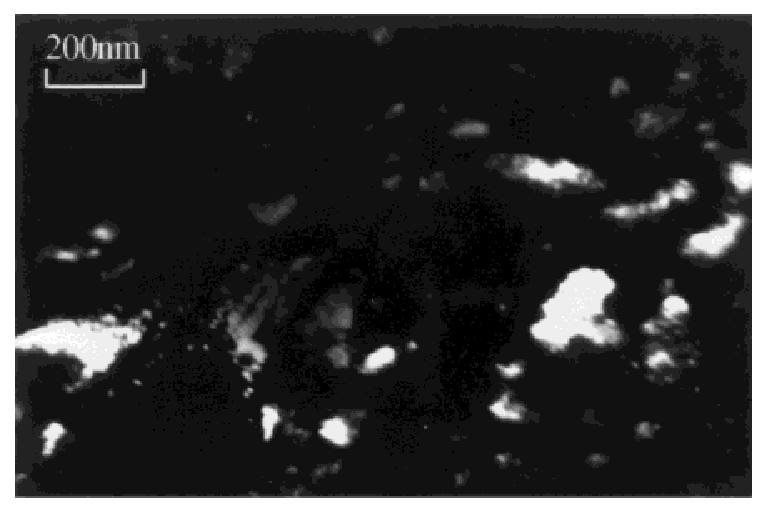

(b)

FIG. 7. Transmission electron micrographs of $3 \times 10^{17} \mathrm{~N}_{2}{ }^{+} / \mathrm{cm}^{2} \mathrm{im}-$ planted PVD TiN taken from a foil from $20 \mathrm{~nm}$ below the surface.

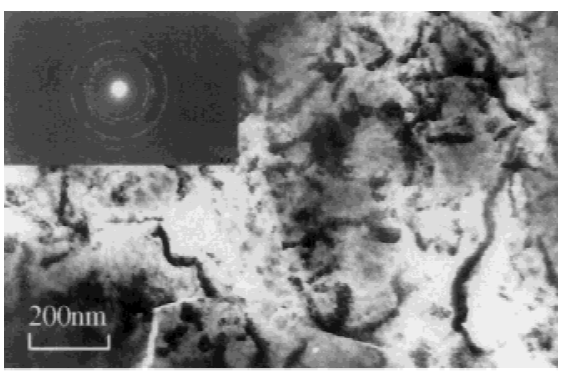

(a)

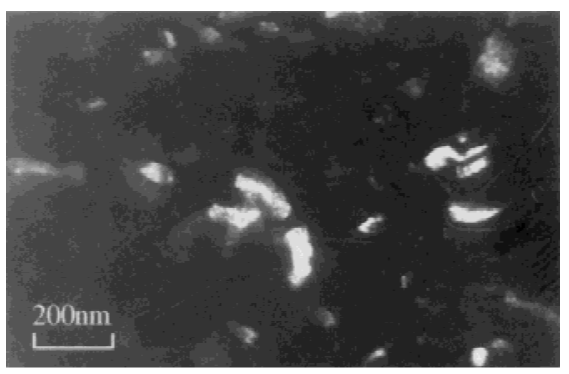

(c)

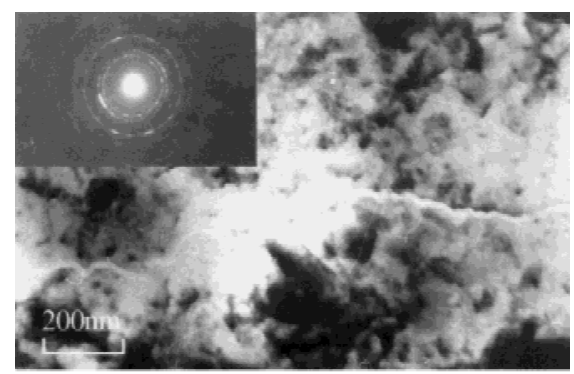

(b)

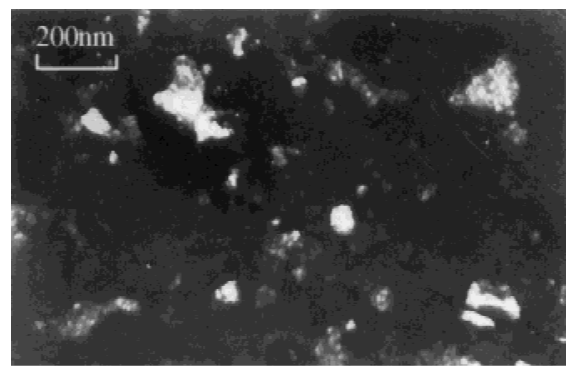

(d)

FIG. 6. Transmission electron micrographs of PVD TiN taken $100 \mathrm{~nm}$ below the sample surface: (a) unimplanted bright field, (b) $1 \times 10^{17} \mathrm{~N}_{2}{ }^{+} /$ $\mathrm{cm}^{2}$ bright field, (c) unimplanted dark field, and (d) $1 \times 10^{17} \mathrm{~N}_{2}{ }^{+} / \mathrm{cm}^{2}$ dark field. 
surface. In the dark-field image [Fig. 7(b)] there are a number of small bright spots that are not present in micrographs from lower dose implanted or unimplanted material. These could be small TiN grains formed by ion-bombardment-induced recrystallization but may also be small nitrogen bubbles where the nitrogen solidified in a well-defined orientation relationship with the TiN. It was not possible to determine which of these is more likely from the samples in this study.

It is not possible to resolve dislocation structures within PVD TiN films because of the much larger number of defects present in these coatings. However, as in the case of the CVD-coated material, long-range effects due to dislocation creation and ejection from the implanted layer are not expected to be significant.

\section{E. Surface topography}

Contact mode AFM scans were used to determine the surface topography for all samples over $10 \times 10 \mu \mathrm{m}$ square regions [Figs. 8(b) and 8(c)]. Ion implantation leads to a slight smoothing of the surface at the lower dose $\left(1 \times 10^{17} \mathrm{~N}_{2}{ }^{+} / \mathrm{cm}^{2}\right)$, which could, in part, explain the reduction in friction [Fig. 8(a)]. However, at the higher dose the roughness increases again. For larger area scans $(100 \times 100 \mu \mathrm{m})$ the roughness is higher and shows no smoothing effect at the lower dose. This shows that smoothing of the asperities occurs, but these are not reduced in size appreciably, a fact confirmed by scanning electron microscopy of the surfaces (Fig. 9).

High dose implantation introduces a substantial amount of extra nitrogen into the coating; for instance, at a dose of $1 \times 10^{17} \mathrm{~N}_{2}{ }^{+} / \mathrm{cm}^{2}$ about 9 at. $\%$ is present at the peak of the nitrogen concentration profile in addition to what is already present in the TiN before implantation. Inspection of the TiN phase-diagram ${ }^{38}$ shows that the equilibrium phases present are nitrogen and $\mathrm{TiN}$, so nitrogen bubbles are expected. Indeed, AFM scans across the nitrogen implantation boundary in the PVD TiN coating implanted with $1 \times 10^{17} \mathrm{~N}_{2}{ }^{+} / \mathrm{cm}^{2}$ reveal an enormous expansion of the implanted layer (Fig. 10), which might be expected if it is full of bubbles as has previously been observed in nitrogen implanted silicon. ${ }^{24}$ The expansion is on the order of $400 \mathrm{~nm}$, which is more than 10 times the changes in surface roughness introduced by the $1 \times 10^{17} \mathrm{~N}_{2}{ }^{+} / \mathrm{cm}^{2}$ implantation treatment. A soft, spongy bubble layer would have a relatively low hardness, as was observed for this sample (Fig. 2). As the nitrogen dose increases, bubble formation will also increase. Eventually, the pressure in the bubbles is sufficient to exfoliate regions of the surface layer (Fig. 11). This generates a considerably roughened surface with the increase
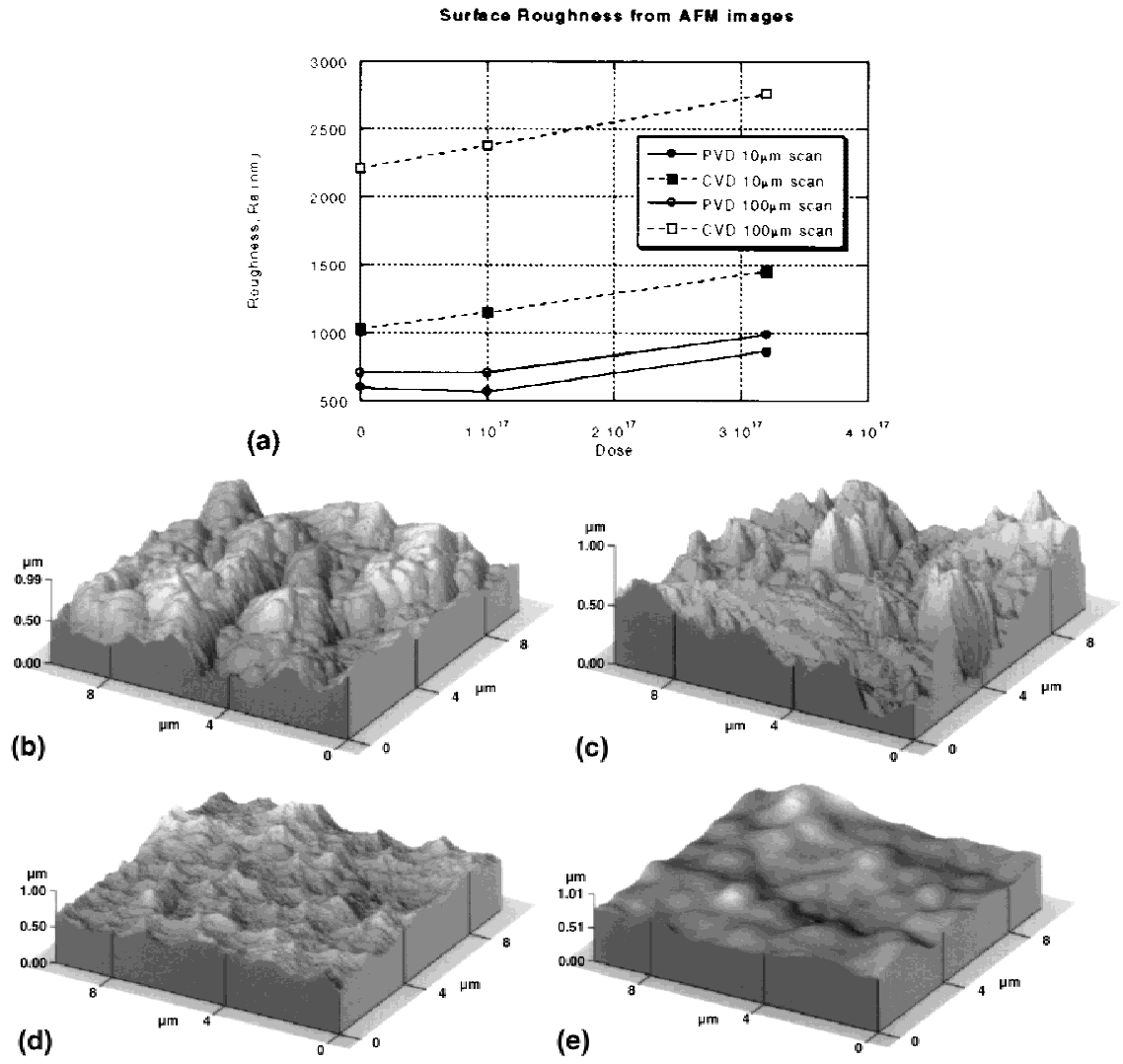

FIG. 8. (a) Variation of roughness with dose determined from AFM scans on nitrogen-implanted PVD and CVD TiN. Contact mode AFM images of coating surfaces of (b) unimplanted, (c) $1 \times 10^{17} \mathrm{~N}_{2}{ }^{+} / \mathrm{cm}^{2}$ implanted CVD TiN, (d) unimplanted, (e) $1 \times 10^{17} \mathrm{~N}_{2}{ }^{+} / \mathrm{cm}^{2}$ implanted PVD TiN. 
in $\mathrm{Ra}$ approaching the thickness of the expanded implanted layer (Fig. 8). This would also explain previous observations that the amount of nitrogen remaining in TiN after implantation to $2 \times 10^{17} \mathrm{~N}_{2}{ }^{+} / \mathrm{cm}^{2}$ is much less than expected (approximately 5\% as opposed to 35\%) and the concentration profile is much nearer to the surface. ${ }^{9}$ Compositional depth profiles from exfoliated samples show little evidence that implantation has taken

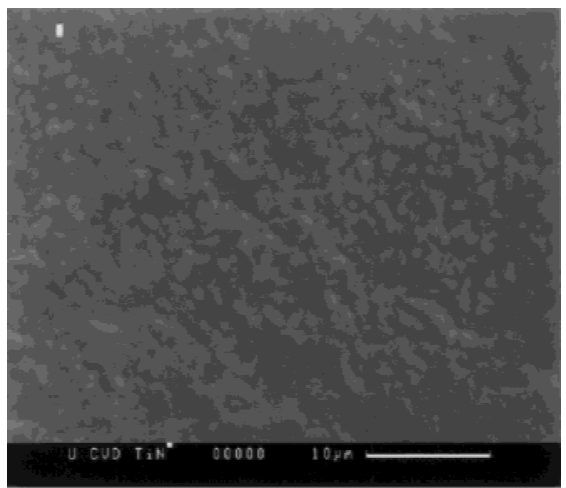

(a)

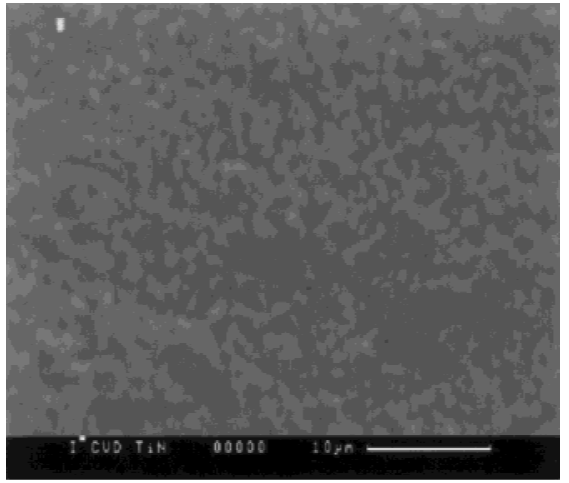

(c)

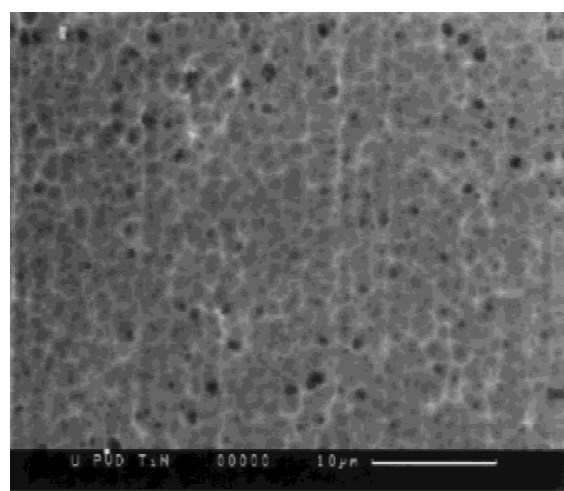

(b)

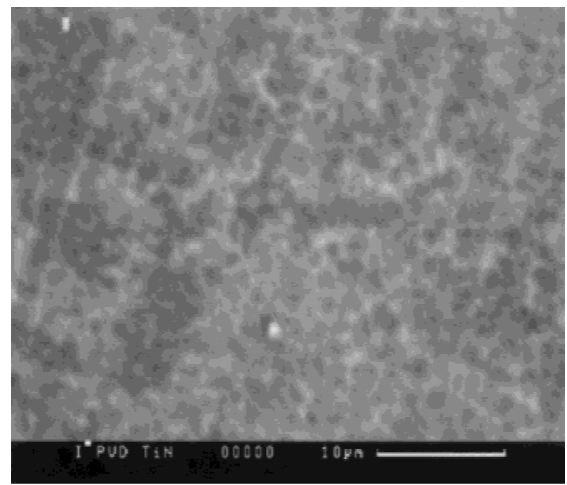

(d)

FIG. 9. Scanning electron micrographs of the surface of CVD TiN: (a) unimplanted and (c) $1 \times 10^{17} \mathrm{~N}_{2}{ }^{+} / \mathrm{cm}^{2}$ implanted. (b,d) The corresponding micrographs for PVD TiN.

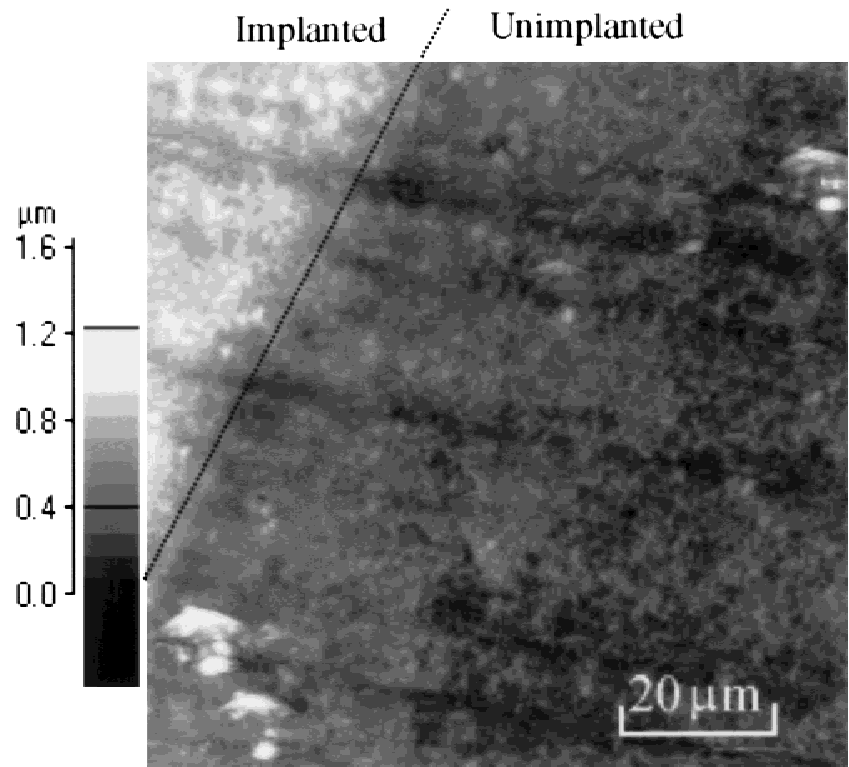

FIG. 10. AFM image of the boundary between $1 \times 10^{17} \mathrm{~N}_{2}{ }^{+} / \mathrm{cm}^{2}$ implanted and unimplanted PVD TiN.

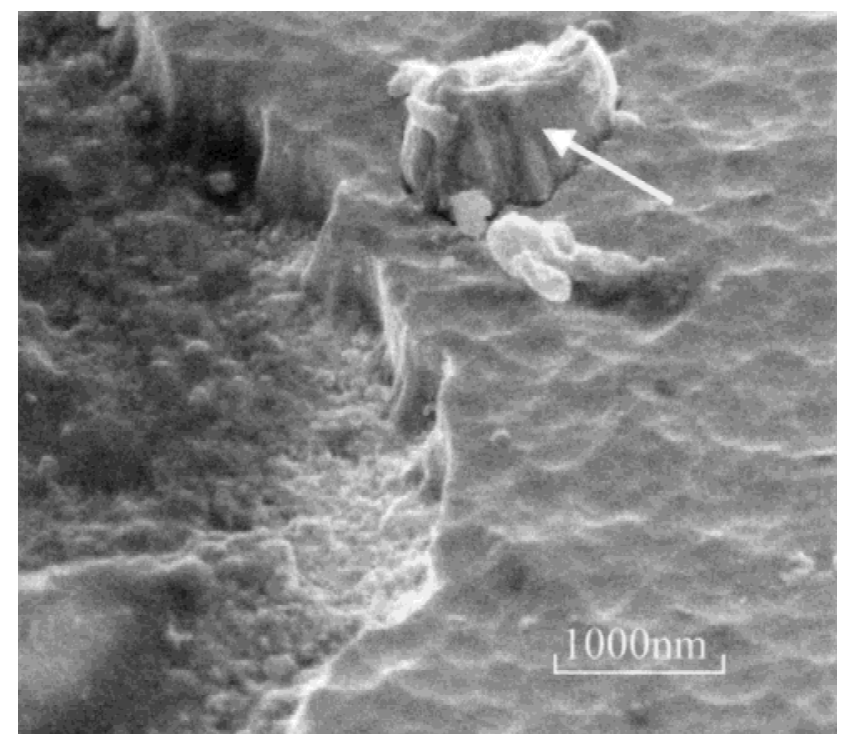

FIG. 11. Scanning electron micrograph showing the edge of an exfoliated region. The bottom of the exfoliated pit is rougher than the original surface. Note the present of a blister (arrowed) that has not yet become detached. 
place, implying that most of the implanted material has been removed with the exfoliated layer. Thus, exfoliation probably occurs in the vacuum system toward the end of the implantation cycle or on removal of the samples at the end of the process and the ejected TiN debris is lost.

\section{F. Why is friction lower after implantation?}

The work presented so far has highlighted changes to friction and adhesion of the tool to the workpiece as the most important factor in dictating wear performance. However, this is not due to amorphization of $\mathrm{TiN}$ as reported by other workers. ${ }^{7-9}$ There was no evidence for amorphization in this study, and it is difficult to envisage how a material such as TiN can be amorphized without implantation of a metalloid such as boron, since the bonding is substantially metallic. High-dose implantation of metals generally results in the generation of dislocation, recovery, and recrystallization rather than amorphization, ${ }^{17}$ and there is some evidence for grain refinement in this study for high dose implantation (Fig. 12). However, amorphization has been reported by previous workers and there could be a couple of reasons for these observations: (i) implanted layers are $\mathrm{x}$-ray amorphous (i.e., show no peaks just very broad features) but are actually crystalline with a very fine grain size less than the $\mathrm{x}$-ray coherence length (around $10 \mathrm{~nm}^{39}$ ); (ii) the TiN coatings have a relatively thick amorphous layer produced on their surface during ion implantation. This could be an oxide layer $\left(\mathrm{TiO}_{2}\right)$ amorphized by nitrogen ion implantation or an amorphous carbon layer produced by the cracking of diffusion pump oil. ${ }^{40}$

If no amorphous layer is observed and the changes in surface topography are not enough to explain the reduction in friction, then the only other factor that can explain the results is changes in surface composition/adhesion. A dark surface is produced after nitrogen implantation of

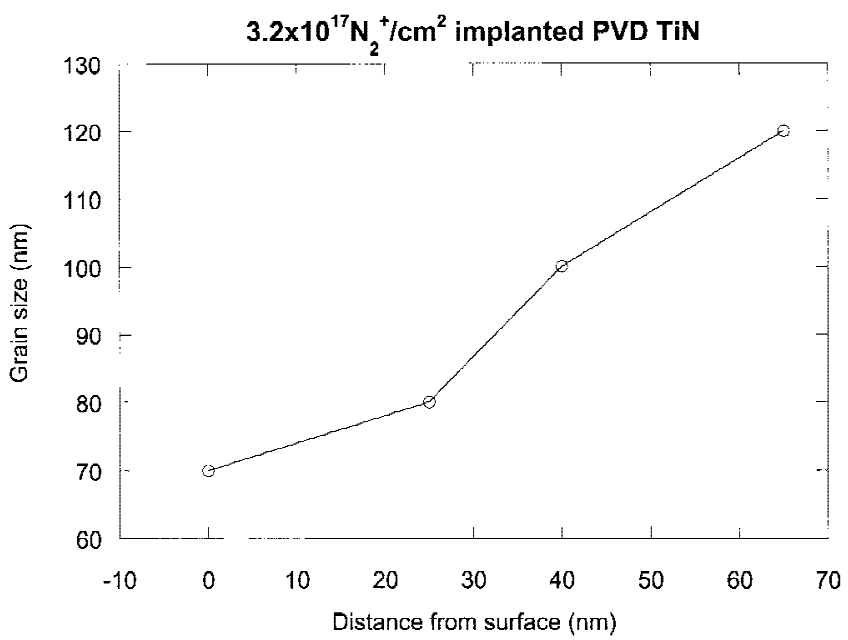

FIG. 12. Variation of grain size with depth below the surface for $3.2 \times 10^{17} \mathrm{~N}_{2}{ }^{+} / \mathrm{cm}^{2}$ implanted PVD TiN.
TiN, which is formed by preferential sputtering of nitrogen as has been reported previously. ${ }^{4}$ However, other composition changes also occur due to the vacuum system in which the coatings are implanted. Most commercial implantation systems do not operate at high vacuum, and the pressure is high enough that hydrocarbons and water vapor will be deposited on the coating surface from the vacuum chamber continuously during implantation. Auger surface profiles (Fig. 13) show that carbon and oxygen are both incorporated deep into the surface by recoil implantation. In addition, silicon is incorporated in the coating after ion-implantation; this comes from diffusion pump oil which has back-streamed into the chamber and deposited on the sample surface. The incorporation of carbon into $\mathrm{TiN}$ is known to reduce friction, ${ }^{4}$ and oxynitride phases have been found to have good tool properties. Indeed, if enough oxygen is incorporated into the surface layer by recoil implantation, then
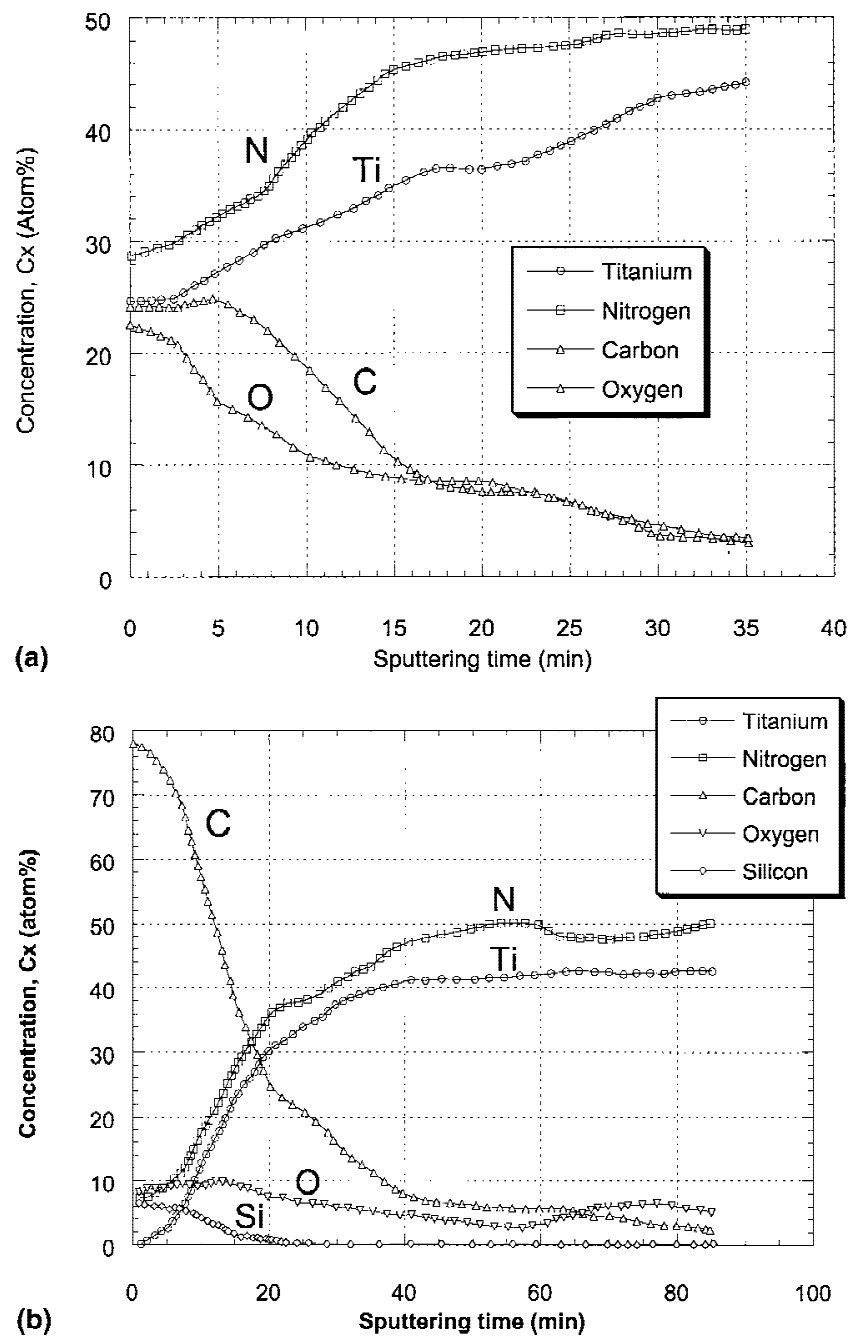

FIG. 13. Auger depth profiles for (a) unimplanted and (b) $3.2 \times 10^{17} \mathrm{~N}_{2}{ }^{+} / \mathrm{cm}^{2}$ implanted PVD TiN. Considerable incorporation of carbon (and to a lesser extent silicon) in the surface has occurred due to the implantation treatment. 
it is very possible that this may be subsequently amorphized and produce the results observed previously. ${ }^{7}$ Similarly, in glancing-angle $\mathrm{x}$-ray diffraction studies where the angle is adjusted to reduce $\mathrm{x}$-ray penetration to less than the implanted layer thickness, the deposition of a very thin layer of amorphous carbon on the surface by ion beam cracking of diffusion pump oil will lead to an apparently amorphous surface. This is consistent with the increasing apparent amorphization of PVD TiN as the glancing angle is reduced, as has been observed previously. ${ }^{35}$ Also since the hardness of this amorphous material will be similar to that of ion beam diamondlike carbon (approximately $15 \mathrm{GPa}^{40}$ ), which is softer than PVD TiN but similar in hardness to CVD TiN, surface softening would be observed only for the PVD TiN as reported previously. ${ }^{9}$

The improved tribological properties of nitrogenplanted TiN are thus likely to arise from the carbon and other species deposited onto the tool surface in the vacuum system of the ion implanter. This will occur irrespective of the source of the coating or the coating process used. A relatively high dose is needed so that a sufficiently thick carbonaceous layer is produced. However, just as in the case of diamondlike carbon coatings produced by the ion beam cracking of diffusion pump oil, the adhesion of the modified layer is relatively poor and it will be detached if its thickness exceeds a critical value. ${ }^{40}$ Thus there is a fixed optimum dose for all tools of $3 \times 10^{17} \mathrm{~N}_{2}{ }^{+} / \mathrm{cm}^{2}$.

\section{CONCLUSIONS}

This work has attempted to identify the factors controlling tool wear performance for nitrogen-implanted TiN and had led to a number of conclusions. Changes in hardness are not sufficient to explain the wear performance of nitrogen implanted TiN. There is no evidence for amorphization in the samples studied here. The formation of nitrogen bubbles leads to a softening and surface detachment at high doses. There is no evidence that changes in residual stress or coating/substrate adhesion contribute to wear performance. Friction is reduced after ion implantation probably due to the incorporation of a large amount of carbon into the surface of the TiN from the diffusion pump oil used in the implanter. Wear improvements are most likely due to these chemical changes introduced by the implantation process.

\section{ACKNOWLEDGMENTS}

The authors would like to thank AEA Technology, Implant Sciences and Dr. Rafi Manory for the provision of implanted samples and useful discussions. The authors would also like to thank Prof. E.V. Kozlov (Tomsk) for useful discussions about the TEM results.

\section{REFERENCES}

1. C.G. Fountzoulas, A. Gonzalez, J.K. Hirvonen, B.D. Sartwell, and F. Lancaster, Surf. Coat. Technol. 84, 574 (1996).

2. R.J. Culbertson, F.C. Burns, W. Franzen, L.J. Lowder, J.J. Ricca, and A. Gonzales, Nucl. Instrum. Methods B56/57, 652 (1991).

3. M. Braun, Nucl. Instrum. Methods B59/60, 914 (1991).

4. A.J. Perry, J.R. Treglio, D.G. Bhat, S.P. Boppana, T.Z. Kattamis, K. Schlichting, G. Dearnaley, and D.E. Geist, Surf. Coat. Technol 68/69, 294 (1994).

5. R.R. Manory, L.J. Liu, D.K. Sood, Z.M. Shao, C. Kylner, and M. Braun, Surf. Coat. Technol. 70, 1 (1994).

6. A.J. Perry, Mater. Sci. Eng. A253, 310 (1998).

7. T.S. Jang and S.W. Lee, Mater. Chem. Phys. 54, 305 (1998).

8. A.V. Kulkarni, N. Matc, S.M. Kanektar, S.B. Ogale, and B.G. Wagh, Surf. Coat. Technol. 54/55, 180 (1992).

9. R.R. Manory, C.L. Li, C. Fountzoulas, J.D. Demaree, J.G. Hirvonen, and R. Nowak, Mater. Sci. Eng. A253, 319 (1998).

10. A.M. Jones, AEA Technology (private communication).

11. J.A. Thornton, Ann. Rev. Mater. Sci. 7, 239 (1977).

12. D.E. Giest, A.J. Perry, J.R. Treglio, V. Valvoda, and D. Rafaja, Adv. X-ray Anal. 38, 471 (1995).

13. D.S. Rickerby, A.M. Jones, and A.J. Perry, Surf. Coat. Technol. 36, 631 (1988).

14. D.S. Rickerby, S.J. Bull, T. Robertson, and A. Hendry, Surf. Coat. Technol. 41, 63 (1990).

15. D.S. Rickerby and S.J. Bull, Surf. Coat. Technol. 39/40, 315 (1989).

16. S.J. Bull, A.M. Jones, A.R. McCabe, A. Saleh, and P. Rice-Evans, in Advances in Surface Engineering Volume II: Process Technology, edited by P.K. Datta and J.S. Burnell-Gray (Royal Society of Chemistry Publication 207, RSC, Cambridge, United Kingdom, 1997), pp. 48-56.

17. M.W. Thompson, Defects and Radiation Damage in Metals, (Cambridge University Press, Cambridge, United Kingdom, 1969).

18. H.M. Naguib and R. Kelly, Rad. Eff. 25, 1 (1975); H.M. Naguib, and R. Kelly, Rad. Eff. 25, 78 (1975).

19. L.J. Liu, D.K. Sood, and R.R. Manory, in Beam-Solid Interactions: Fundamentals and Applications, edited by M.A. Nastasi, L.R. Harriott, N. Herbots, and R.S. Averback (Mater. Res. Soc. Symp. Proc. 279, Pittsburgh, PA, 1993), p. 469.

20. L.J. Liu, D.K. Sood, R.R. Manory, and W. Zhou, Surf. Coat. Technol. 71, 151 (1995).

21. A.J. Perry, R.R. Manory, D. Rafaja, and R. Nowak, Vacuum 49, 89 (1998).

22. D. Rafaja, V. Valvoda, A.J. Perry, and J.R. Treglio, Surf. Coat. Technol. 92, 135 (1997).

23. A.J. Perry and J. Schoenes, Vacuum 36, 149 (1986).

24. P.J. Burnett and T.F. Page, J. Mater. Sci. 19, 845 (1984).

25. P.J. Burnett and T.F. Page, J. Mater. Sci. 19, 3524 (1984).

26. L. Pauling, The Nature of the Chemical Bond (Cornell University Press, Ithaca, 1960).

27. P.J. Burnett and T.F. Page, Rad. Eff. 97, 283 (1986).

28. Yu.P. Sharkeev, A.N. Didenko, and E.V. Kozlovi, Surf. Coat. Technol. 65, 112 (1994).

29. Yu.P. Sharkeev, E.V. Kozlov, A.N. Didenko, S.N. Kolupaeva, and N.A. Vihor, Surf. Coat. Technol. 83, 15 (1996).

30. Yu.P. Sharkeev, A.J. Perry, and S.V. Fortuna, Surf. Coat. Technol. 109, 419 (1998).

31. S.G. Roberts, Ph.D. Thesis, University of Cambridge, Cambridge, United Kingdom (1982).

32. W.C. Oliver and G.M. Pharr, J. Mater. Res. 7, 1564 (1992).

33. S.J. Bull, Tribology Int. 7, 491 (1997). 
34. R.D. Arnell, Surf. Coat. Technol. 43/44, 674 (1990).

35. R.R. Manory, A.J. Perry, D. Rafaja, and R. Nowak, Surf. Coat. Technol. 114, 137 (1999).

36. P.J. Burnett and T.F. Page, J. Mater. Sci. 20, 4624 (1985).

37. S.J. Bull, A. Saleh, P. Rice-Evans, A.J. Perry, and J.R. Treglio, Surf. Coat. Technol. 91, 7 (1997).

38. Metallography, Structures and Phase Diagrams, ASM Metals Handbook, Vol. 8 (ASM, Metals Park, OH, 1973), p. 322.

39. B.D. Cullity, Elements of X-ray Diffraction, 2nd ed. (AddisonWesley, Reading, MA, 1978).
40. A.R. McCabe, G. Proctor, A.M. Jones, S.J. Bull, and D.J. Chivers, in Surface Engineering Volume III: Process Technology and Surface Analysis, edited by P.K. Datta and J.S. Gray (Proc. 3rd Int. Conf. on Advances in Coatings and Surface Engineering for Corrosion and Wear Resistance, (Royal Society of Chemistry, Cambridge, United Kingdom, 1993), pp. 163-175.

41. J.F. Ziegler, J.P. Biersack, and U. Littmark, The Stopping and Range of Ions in Solids (Pergamon Press, New York, 1985).

42. M.J. Norgett, M.T. Robinson, and I.M. Torrens, Nucl. Eng. Design 33, 50 (1975). 